\title{
SELFIE: A IMAGEM ENTRE O ESPETÁCULO E A CONSTRUÇÃO DO SUJEITO
}

Joana Sanches-Justo, Bruna Martins da Silva Alves de Souza, Jaqueline Pereira de Vasconcelos, Tamires Silva Rosa

Universidade do Oeste Paulista - UNOESTE, Cursos de Psicologia e Artes Visuais, Presidente Prudente, SP. Email: joana@unoeste.br

\section{RESUMO}

Este artigo é fruto de uma pesquisa bibliográfica que investigou a produção de selfies na sociedade contemporânea, buscando correlações entre os autorretratos e a construção da identidade pessoal. Discutiu-se a sociedade do espetáculo, a relação do sujeito com a imagem, a formação do indivíduo, consciência e alienação; a partir dos estudos de Debord, Novaes e Duarte. Foi explorada a relação do homem com a imagem, considerando a transformação na nomenclatura das "imagens de si" - de autorretrato para selfie. Posteriormente, foram analisadas fotos de perfis do facebook de adolescentes na tentativa de correlacionar as imagens à construção de identidade e à espetacularização. Entretanto, os dados coletados não forneceram informações suficientes para que fosse estabelecida uma correlação entre o conteúdo das imagens e a construção da identidade como autoafirmação ou impulso à imagem enquanto mercadoria para consumo nas redes sociais e espetacularização do eu.

Palavras-chave: Selfie. Autorretrato. Sociedade do espetáculo. Identidade. Contemporaneidade.

\section{SELFIE: THE IMAGE BETWEEN THE SPECTACLE AND THE SUBJECT CONSTRUCTION}

\begin{abstract}
This article is a research's result that investigated the production of selfies in contemporary society, seeking correlations between self-portraits and the construction of personal identity. The research discussed the society of the spectacle, the subject's relation to the image, the formation of individual consciousness and alienation; from studies of Debord, Novaes and Duarte. It was presented and discussed man's relationship with the image, considering the change in the nomenclature of "images of themselves" - self-portrait to selfie. Subsequently we discussed teenagers facebook profiles' photos in an attempt to correlate the images to the construction of identity and spectacle. However, the data collected did not provide sufficient information to enable a correlation between the image contents and the construction of identity as self-assertion or as merchandise for consumption on social networks and self spectacularization.
\end{abstract}

Keywords: selfie. Self-portrait. society of the spectacle. Identity. Contemporaneity. 


\section{INTRODUÇÃO}

A palavra selfie nomeia de forma popular o autorretrato contemporâneo, fenômeno que obteve grande difusão por meio da globalização, fazendo com que a palavra selfie, fosse a palavra inglesa mais utilizada no ano de $2013^{1}$, mostrando assim sua ampla disseminação em redes sociais.

A sociedade contemporânea adotou a selfie ${ }^{2}$ como forma de auto retratação imagética e o fenômeno ganhou espaço a partir da facilidade de sua produção, aliada às características da sociedade contemporânea de fugacidade, impermanência, imediatismo, aceleração (VIRILIO,1996; ROUANET, 1993). Virilio (1996) articula a lógica da corrida com o enriquecimento: o ritmo acelerado com que se executam os afazeres cotidianos são equivalentes de riqueza e sucesso, cristalizados em chavões como "tempo é dinheiro".

Neste contexto, discutir a produção de selfies é uma forma de tentar compreender e correlacionar a produção de fotos de si com a construção da sujeito e sua singularidade (ou perda dela) na contemporaneidade, buscando discutir se a selfie pode ser um suporte para a formação da identidade do sujeito ou se, por outro lado, é decorrência de uma exposição deliberada da imagem de si como forma de mercadoria para a sociedade do espetáculo.

Para fundamentar esta discussão, podemos propor uma articulação entre a filosofia marxista que embasa a psicologia histórico cultural e a crítica debordiana da sociedade. Debord (2003) caracteriza a sociedade contemporânea enquanto espetáculo do eu, em que o que se pretende alcançar através da imagem é a aparência, em detrimento da existência real.

É importante considerar a mudança na nomenclatura, e talvez no conceito, de autorretrato para selfie. Provavelmente a adoção do termo selfie no Brasil esteja correlacionada a uma maior inserção de palavras estrangeiras no cotidiano da nossa língua. Ainda assim, nos parece que a utilização deste termo indica, mais do que uma inserção no vocabulário, uma prática social - na medida em que outros recursos são agregados à tomada de fotografias selfie, como por exemplo o "pau de selfie". Assim, questionamos: que importância tem a selfie hoje para os adolescentes? Como se configura a relação do sujeito com as selfies, em termos de consumo ou de deciframento das imagens?

\section{METODOLOGIA}

Foi feita uma pesquisa bibliográfica de natureza exploratória, que visou conhecer as contribuições científicas existentes a respeito do tema através de Artigos científicos retirados de duas bases de dados, sendo elas PepPsic e Scielo; Dissertações de mestrado e Teses de doutorado.

A complementação da coleta dos dados seria realizada na rede social Facebook, em que alguns perfis foram consultados na busca de selfies postadas como imagem do perfil do usuário da rede. Foram utilizados 25 perfis femininos e 25 perfis masculinos totalizando 50 perfis participantes e 100 fotografias utilizadas.

Para selecionar perfis públicos no Facebook, foi criada uma nova conta na rede social sem vínculos de amizades; páginas curtidas; comunidades ou aplicativos, para que a pesquisa de usuários não ficasse tendenciosa. O critério de escolha dos usuários do Facebook envolveu os seguintes aspectos:

a) Perfil público; - passível de visualização pública.

b) Indivíduos entre 15 aos 25 anos;

c) Residentes em uma cidade do interior do Estado de São Paulo.

\footnotetext{
${ }^{1}$ Segundo o dicionário inglês Oxford. <http://www.bbc.co.uk/portuguese/noticias/2013/11/131119_Selfie_oxford_fn>.

${ }^{2} \mathrm{~A}$ palavra selfie está relacionada ao ato de tirar fotos de si mesmo, ou seja, corresponde ao termo autorretrato. $\mathrm{O}$ termo selfie, cuja origem é inglesa, teve entrada no vocabulário de língua portuguesa em virtude do seu largo emprego nas redes sociais. A força de uso do vocábulo selfie justifica a sua inclusão no dicionário como nome do gênero feminino. Verifica-se, no entanto, que ainda há alguma hesitação na fixação do gênero, podendo ocorrer também no masculino. Neste trabalho o uso referente a "fotografia" ditará o gênero feminino do termo selfie. <http://www.soportugues.com.br/secoes/curiosidades/Curiosidades_Selfie.php>.
} 
O critério de escolha das duas selfies por perfil analisadas foram:

a) Data de postagem - Sendo priorizadas as duas fotos mais recentes.

b) Fotos tiradas de si mesmo sozinho (a).

As fotografias foram observadas e analisadas dentro da própria rede social, sem a necessidade de terem sido impressas ou reproduzidas fora deste contexto.

\section{RESULTADOS}

$\mathrm{Na}$ tentativa de coletar os dados, não foi alcançado o número estipulado de perfis abertos na faixa etária de 15 a 17 anos, por este motivo os parâmetros da busca foram modificados. 0 novo parâmetro de coleta passou a abranger a faixa etária dos 15 aos 25 anos de idade. Para tornar a busca por esses perfis o mais aleatória possível, levantou-se a hipótese de que as escolhas dos nomes desses indivíduos poderiam estar correlacionadas ao espetáculo da dramaturgia, ou seja, as novelas principalmente da década de 90.

Foi realizada a primeira parte da coleta de dados, que foi a escolha do modo como deveriam ser coletados estes perfis, e dos nomes escolhidos. A partir deste parâmetro foi criada uma relação dos nomes mais populares nos seguintes anos:

No ano 1991 os nomes femininos e masculinos que estão relacionados a personagens da novela Vampi são respectivamente: Daniela, Juliana, Patrícia, Carol, Fernanda e João, Felipe, Pedro, Daniel, Rafael, Diogo.

Em 1993 os nomes femininos e masculinos que estiveram relacionados a personagens da novela Mulheres de Areia são respectivamente: Gabriela, Andrea, Isadora, Raquel, Joana; e Guilherme, João, Daniel, Pedro, Rafael, Paulo.

Já no ano 1994/95 os nomes femininos e masculinos que estiveram relacionados a personagens da novela A Viagem são respectivamente: Fernanda, Yara, Thais, Keila, Denise; e Guilherme, Renato, Daniel, Eduardo.

No ano 1996/97 os nomes femininos e masculinos que estiveram relacionados a personagens da novela O Rei do Gado são respectivamente: Rafaela, Luana, Giovana, Letícia; e Bruno, Marcelo, Marcos e Fabio.

E, por fim, no ano 1999/2000 os nomes femininos e masculinos que estiveram relacionados a personagens da novela Terra Nostra são respectivamente: Ana, Paula, Mariana, Carolina, Paola, Luiza; e Gabriel , Thiago , Antonio, André.

A busca de selfies nos perfis de jovens com os nomes elencados encontrou como obstáculo a pequena disponibilidade de perfis abertos (ou públicos) disponíveis no Facebook, sendo assim, os dados complementares provenientes desta rede social foram insuficientes para uma discussão significativa.

Ainda assim, notou-se, a partir da pesquisa pelos nomes de novela, colocamos em questão a influência da novela (os nomes de personagens e de atores) na escolha dos nomes das crianças nascidas no ano de transmissão destes shows televisivos. Através da televisão o espetáculo - não o teatral, mas esse mais invisível, o espetáculo da primazia da aparência - se enraíza no cotidiano e na identidade dos sujeitos. Em nome da identificação com um personagem ou artista famoso, a criança é nomeada pelos pais. Será essa nomeação uma aposta na fama destes recém-nascidos? Uma identidade marcada pelo espetáculo na mais tenra idade?

Ou, nos aprofundando nestas questões, estaríamos todos submetidos a esta alienação desde o nascimento, independente dos nomes de novela? Protagonistas, cada um, de nossa própria novela espetacular e cotidiana...

\section{DISCUSSÃO}

Considerando que a construção particular de cada "novela cotidiana" se pauta primeiramente na construção de uma identidade fundada em um tempo de supervalorização da 
imagem e da aparência, é importante contextualizar a relação do homem com a imagem, para pensarmos a construção da identidade do adolescente.

Segundo Nones e Moreira (2014) a tradição ocidental possui uma tendência maior à elaboração de imagens, obtidas por meio dos retratos e autorretratos nas pinturas, mas é a partir do Renascimento que a arte é invadida pela fotografia, que em primeiro momento a semelhança imagética gerava desconforto ao passar uma ideia de sequestro. Considerada uma ferramenta mediadora, gerou polêmica no âmbito Crítico Artístico, uma vez que evidenciava a habilidade mecânica em detrimento da humana.

Ao ser associada à pintura, a fotografia tornou-se apenas uma representação e não um "decalque da realidade". Aos poucos, o sentimento de sequestro deu lugar à ideia de eternização (SANCHES-JUSTO, 2013). Baseada na premissa de fidelidade a realidade, a fotografia é considerada como documento, prova (SANCHES-JUSTO, 2014). Assim, uma fotografia de si mesmo pode ser utilizada como meio de auto representação e prova de existência.

Nesse contexto, mais além de provar a existência de um sujeito, a produção de selfie pode estar intimamente relacionada à produção de mercadorias em uma sociedade do espetáculo, na medida em que busca atender a demanda social através de um processo de "tratamento" e manipulação da imagem. Com o poder de manipular uma imagem, pode-se "parecer" o que quiser. Aí se realiza a máxima da sociedade do espetáculo.

Debord (2003) fala em sua tese de número 4 que "O espetáculo não é um conjunto de imagens, mas uma relação social entre pessoas mediadas por imagens" (DEBORD, 2003, p. 14). 0 consumo da imagem sem a devida reflexão, arranca do objeto seu valor pleno e o divide com sua própria representação. Representação esta que nem sempre é fiel a realidade, mas que é uma releitura devidamente manipulada da realidade compartilhada.

Esse vínculo social com o consumo substitui a antiga degradação do ser em detrimento do ter, atualmente o ter já não é mais suficiente, ele deve ser suprido pelo aparecer ou pelo parecer que é e, ainda nesta perspectiva, é possível falar sobre alienação em detrimento da reflexão mediante ao consumo da mercadoria (SANCHES-JUSTO, 2014).

$\mathrm{Na}$ perspectiva de Debord (2003), tanto o produtor da imagem quanto o consumidor correm o risco de cair na alienação. No caso da selfie, produtor e objeto da retratação se confundem sendo que é o próprio objeto retratado que produz a representação. A produção de selfie é um elemento intermediário, entre o indivíduo e sua a autoimagem. Na produção da selfie, encontra-se um paradoxo já que o autor é o próprio objeto fotografado. Neste sentido, poderíamos dizer que o autor de uma selfie atinge o máximo de alienação?

Nones e Moreira (2014) salientam que o autorretrato possui esta característica singular por permitir que o fotógrafo se relacione de uma forma mais íntima com sua produção, logo se relacione mais intimamente com a imagem de si produzida. A selfie tomada como intimidade e encontro do sujeito consigo mesmo romperia a alienação própria da produção de imagens?

Para discutir se esta produção é parte da construção da identidade na adolescência, ressaltamos que esta fase é perpassada por uma construção histórica, portanto, permeada por diferentes visões a respeito da adolescência constituídas ao longo do tempo.

A mudança na concepção de adolescência só foi, e é, possível porque esta é uma fase do desenvolvimento humano que nem sempre existiu, a adolescência é fruto de mudanças sociais mudanças no modo de produção. Assim, a Psicologia histórico-cultural entende o ser humano como um produto construído culturalmente. A visão naturalizante do homem, tem um cunho biologicista que naturaliza também a adolescência. Nesta visão, a adolescência é reduzida a uma época de transtornos e mutações corporais que leva em consideração apenas as características biológicas como sendo determinantes no desenvolvimento.

Elkonin (apud. DOS ANJOS, 2013) busca a integração entre processos biológicos e culturais para melhor compreender o desenvolvimento humano. Dos Anjos (2013), relembra que a 
adolescência não é algo natural ao ser humano, mas pelo contrário é fruto de mudanças na sociedade e suas divisões em classes sociais. Explica que a rebeldia por parte dos adolescentes se justifica no seu afastamento forçado da vida adulta e do trabalho.

Para Vigostski o desenvolvimento psicológico na adolescência, se difere da infância em seus interesses pode ser chamada de "Viragem", em que é regido por uma nova forma de pensar e por novos interesses (DOS ANJOS, 2013). A viragem impele o indivíduo a uma redefinição da própria identidade, baseado na avaliação de seu atual contexto - tempo, espaço - onde ele será capaz de integrar situações já vivenciadas com suas perspectivas e antecipações de futuro. $\mathrm{O}$ autor pontua ainda que a principal atividade na adolescência passa a ser a comunicação intima pessoal, através desta é que se forma a autoconsciência, aquilo que primeiramente era exterior, é internalizado para se tornar parte do sujeito.

Isto significa dizer que o desenvolvimento psíquico do adolescente, é fruto daquilo que the é transmitido pelos adultos, transmissão das experiências sociais já acumuladas pela humanidade. Neste sentido, podemos de fato considerar que a nomeação a partir de um personagem de novela ou ator, traz consigo uma marca, uma expectativa, uma história que compõe a construção da identidade desta criança. Para além dos bebês nomeados a partir dos astros televisivos, cabe notar que toda criança traz em si uma marca, um atravessamento familiar, social e histórico que vai ajuda-la a compor sua "novela cotidiana", sua identidade.

\section{CONCLUSÃO}

Assim, retomamos as questões que nortearam a pesquisa: como se configura a relação do adolescente com as selfies, em termos de consumo ou de deciframento de imagens?

O consumo de imagens envolve a submissão do sujeito a um ideal imagético e de comportamento socialmente imposto. É ditado o que deve ser consumido, como devem ser as características pessoais deste sujeito e como ele deve parecer que é. Cada indivíduo não apenas consome imagens, como também produz imagens para consumo em forma de selfie, tendo as redes sociais como veiculo de difusão das imagens.

Nesse sentido parece muito pouco provável que a selfie possa ser um instrumento de autoconhecimento ou de deciframento de si. Imersa em um mundo que prima as aparências, a selfie pode se configurar como mais uma mercadoria para o consumo desenfreado, objetos de mero gozo escópico, fetiche, mercadorização do eu.

Ainda assim, não podemos encerrar tão prontamente a questão. A produção de imagens, na medida em que possibilita o sujeito olhar-se a si mesmo ali nas imagens que produz e veicula na rede, pode estar rumo a novas apropriações do uso da imagem, produções que estejam relacionadas a um modo específico de o adolescente, neste tempo e cultura, dizer-se, mostrar-se, pensar-se - através de selfies.

A selfie como uma forma de espetáculo ou como uma construção de si na contemporaneidade é uma questão que merece ser deixada em aberto. A partir desta pesquisa consideramos que os elementos retratados em uma fotografia não podem ser tomados como indicadores de uma intenção do sujeito de um "parecer" em detrimento do "ter", mas podemos afirmar que a popularidade da selfie e sua produção maciça nos dias atuais é um fenômeno que traz à tona o conceito de sociedade do espetáculo defendido por Guy Debord. Tampouco pode-se afirmar ao analisar uma fotografia que o indivíduo utiliza-se deste recurso para sentir-se pertencente a um grupo, como noção de identidade, pois é uma construção com diversos atravessamentos: particulares, sociais, culturais, históricos. Contudo, a imagem, a fotografia, a selfie e sua divulgação nas redes sociais fazem parte desta construção.

Com base nessa discussão, cabe sustentar a questão acerca do "por que produzimos selfies?", pergunta esta que pode ser refletida, indagada e respondida em outras pesquisas e artigos, mas também individualmente, na singularidade de cada construção. 


\section{REFERÊNCIAS}

BOCK, A. M. B. A perspectiva sócio-histórica de leontiev e a crítica à naturalização da formação do ser humano: A adolescência em questão. Cad. Cedes, Campinas, vol. 24, n. 62, p. 26-43, abril 2004. Disponível em <http://www.cedes.unicamp.br>

DEBORD, G. A Sociedade do Espetáculo. Versão em pdf. www.geocities.com/projetoperiferia: Projeto Periferia, 2003. Disponivel em: <http://www.ebooksbrasil.org/eLibris/socespetaculo.html> Acesso em: 15.out. 2014.

DOS ANJOS, R. E. O desenvolvimento psíquico na idade de transição e a formação da individualidade para-si: Aportes teóricos para a educação escolar de adolescentes. 2013. $167 \mathrm{f}$. Dissertação (Mestrado em Educação) - Faculdade de Ciências e Letras, Universidade Estadual Paulista, Campus Araraquara - SP.

DUARTE, Newton. Formação do indivíduo, consciência e alienação: o ser humano na psicologia de A. N. Leontiev. Cad. CEDES, Campinas, v. 24, n. 62, abr. 2004 . Disponível em <http://www.scielo.br/scielo.php?script=sci_arttext\&pid=S010132622004000100004\&lng=pt\&nrm=iso >. Acesso em: 01 nov. 2014.

OLIVEIRA, Marta Kohl. Vygotsky. Aprendizado e Desenvolvimento. Um processo sócio-histórico. São Paulo: Scipione, 1993.

MIRANDA, L. A. de. Corpo para mostrar: o autorretrato nas redes sociais. In: III Encontro Baiano de Estudos em Cultura, Cachoeira, 2012. Anais III Encontro Baiano de Estudos em Cultura. Universidade Estadual de Feira de Santana, Cachoeira, 2012.

NEGRINI M; AUGUSTI A. R. O legado de Guy Debord: reflexões sobre o espetáculo a partir de sua obra, 2013. Disponível em: <http://www.bocc.ubi.pt/pag/negrini-augusti-2013-legado-guydebord.pdf>. Acesso em: 10 nov. 2014.

NONES L.; MOREIRA F. R. Autorepresentação entre linguagens artísticas. Revista de Iniciação Científica, Tecnológica e Artística, São Paulo, vol. 4, n. 1, p. 1-10, Abr. 2014.

ROUANET, S. P. A Razão Nômade. Rio de Janeiro: Editora UFRJ, 1993.

SANCHES-JUSTO, J. $\mathbf{O}$ ato fotográfico: memória, prospecção e produção de sentidos na velhice. São Paulo: Cultura Acadêmica, 2013.

SANCHES-JUSTO, J. A primazia da imagem e a virtualização das relações na cultura das aparências. Revista Espaço Acadêmico, n. 153, Fev. 2014.

VIRILIO, P. Velocidade e política. São Paulo: Estação Liberdade, 1996. 